PALAVRAS. Revista de Epistemología, Metodología y Ética del Psicoanálisis

ISSN: 2468-9831

www.revistas.unlp.edu.ar/palavras

palavras@outlook.com.ar

Argentina

\title{
SOBRE LA NATURALEZA DEL DESEO Y LA SUBJETIVIDAD: LA CRIITICA ESQUIZOANALÍTICA AL PSICOANÁLISIS FAMILIARISTA
}

DOI: $10.24215 / 24689831 \mathrm{e} 022$

Ivo Krasutzky

\begin{abstract}
This work is a reading and exegesis of some ideas about the nature of desire and subjectivity, which are read from a problematic field that produces the category of subjectivity as a transdisciplinary object, and that points to ourselves what we are and our constitution, such as materiality of said object. Freud's Psychoanalysis is one of the most precise sources in the analysis of the different theories that contribute to think about subjectivity, a theory that, through the concepts of the unconscious, psychic apparatus and sexual economy, marks a possible route to embark in the problematic of subjectivity. Some of Freud's conceptualizations about the nature of desire and its functioning in the constitution of psychic apparatus are presented, including the function and characteristics of the Oedipus complex as an intervening process. Then some parts of the criticism that Deleuze and Guattari make in their book The Anti-oedipus are exposed, a selection that aims to accentuate the criticism regarding familiarity, and the consequent operation of reduction, in the theorizations of the Freudian psychoanalysis on desire and the psychic constitution. Finally, synthesizing the consequences of schizoanalytic criticism, a notion of machinic subjectivity is briefly described, where desire as an immanent principle, in its circulation, goes beyond and determines the family, scenario of the Oedipus complex, thinking of the desire connected to the social field as a whole.
\end{abstract}

Key-words: desire - subjectivity - Freud -

schizoanalysis - Oedipus
Resumen

Este trabajo es una lectura y comentario de algunas ideas sobre la naturaleza del deseo y la subjetividad, las cuales son leídas desde un campo problemático que produce a la categoría de subjetividad como objeto trasdisciplinario, y que señala a nosotros mismos, lo que somos y nuestra constitución, como la materialidad de dicho objeto. El psicoanálisis de Freud es una de las fuentes más precisas en el análisis de las diferentes teorias que aportan insumos al pensamiento sobre la subjetividad, teoría aquella que, mediante los conceptos de inconsciente, aparato psíquico y economía sexual, baliza un recorrido posible para embarcarse en la problemática de la subjetividad. Se presentan primero algunas de las conceptualizaciones de Freud acerca de la naturaleza del deseo y su funcionamiento en la constitución de aparato psíquico, incluyendo la función y características del complejo de Edipo como proceso interviniente. Luego se exponen algunas partes seleccionadas de la crítica que Deleuze y Guattari realizan en su libro El Antiedipo, selección que pretende acentuar la crítica respecto del familiarismo, y la consecuente operación de reducción, en las teorizaciones del psicoanálisis freudiano sobre el deseo y la constitución psíquica. Finalmente, sintetizando las consecuencias de la crítica esquizoanalitica, se describe someramente una noción de subjetividad maquínica, en donde el deseo como principio inmanente, en su circulación, rebasa y determina a la familia, escenario del complejo de Edipo, pensando al deseo como conectado al campo social en su conjunto.

Palabras clave: deseo - subjetividad - Freud esquizoanálisis - Edipo

Cómo citar este artículo:

Krasutzky, I. (2018). Sobre la naturaleza del deseo y la subjetividad: la crítica esquizoanalítica al psicoanálisis familiarista. Palavras. Revista de Epistemología, Metodología y Ética del Psicoanálisis, 4, 14-24. Recuperado de http://www.revistas.unlp.edu.ar/palavras 


\section{SOBRE LA NATURALEZA DEL DESEO Y LA SUBJETIVIDAD: LA CRÍTICA ESQUIZOANALÍTICA AL PSICOANÁLISIS FAMILIARISTA DE FREUD}

\section{Ivo Krasutzky *}

\section{Introducción}

La subjetividad constituye un objeto problemático transversal a distintos ámbitos de conocimiento, y se establece como un concepto trasdisciplinario, y por ende, polisémico. En este trabajo, la subjetividad se presenta como concepto inespecífico general para remitir a lo que en Freud se menciona como aparato psíquico o psiquismo, y máquina deseante en El Antiedipo de Deleuze y Guattari. Y será el significante sobre cuyo contenido se debate, al desarrollar parcialmente la crítica de los autores a la concepción de deseo en Freud.

Se seleccionan algunos fragmentos del psicoanálisis freudiano acerca de la naturaleza del deseo, su funcionamiento en la constitución del aparato psíquico y el lugar del complejo de Edipo en la estructuración de la economía deseante. Sobre esta referencia freudiana acerca del deseo, se describe una lectura y crítica de Deleuze y Guattari, denunciando entre otros aspectos una posición reaccionaria frente al descubrimiento del deseo. Como motor del psiquismo, de la tendencia a la satisfacción, del ejercicio de las investiduras en las relaciones de los objetos, la crítica a la concepción de deseo en Freud, presente en El Antiedipo, se focaliza en la determinación y gravedad marcada por el llamado complejo de Edipo.

Esta crítica presenta varias aristas, entre las que se incluyen la crítica a la representación, y las tendencias normalizadoras presentes en la obra freudiana. En este trabajo la atención se centra en la crítica sobre el familiarismo, es decir, el papel fundamental adjudicado a las relaciones

\footnotetext{
* Facultad de Psicología, Universidad Nacional de La Plata, Argentina. Mail: ivokrasutzky@hotmail.com
} 
familiares en el desarrollo de la economía libidinal. Por eso esta crítica pretende ser utilizada como insumo a una concepción distinta de la freudiana respecto del deseo, noción que amplía las bases de funcionamiento y espacio de acción del deseo, conectándose al campo social en su totalidad, entre cuyos elementos se encuentra también, pero no exclusivamente, la familia. A nuestro beneficio, la crítica presenta una propuesta teórica que hace el esfuerzo por diferenciarse de posturas deterministas o universales sobre el deseo, y considera en su análisis los distintos planos y ordenes de la existencia en la producción deseante; y por ende, en la producción de subjetividad en su variedad y variación esencial.

\section{El reconocimiento al descubrimiento freudiano del deseo, y el complejo de Edipo como reacción familiarista}

Desde los inicios de sus trabajos, Deleuze y Guattari han establecido con el psicoanálisis un acercamiento fértil, produciendo un territorio conceptual en donde el deseo ocupa un lugar privilegiado para el análisis del campo inmanente de la producción de lo real. Deleuze y Guattari reconocieron en Freud la virtud de su descubrimiento: el papel de la energía sexual o libido operando en la determinación de las relaciones interpersonales, postulando al deseo como categoría ontológica y teórica que describe aquello inconsciente que sustenta y moviliza los procesos deseantes en su totalidad: producciones del inconsciente, investiduras en relaciones con objetos parciales, tendencia a la satisfacción de pulsiones. Freud afirma: "El psicoanálisis reconoció pronto que todo acontecer anímico debía edificarse sobre el juego de fuerzas de las pulsiones elementales." (Freud, 1923/1976: 250).

Mediante los puntos de vista tópico, económico y dinámico de la teoría, el psicoanálisis freudiano postula la presencia de intercambios y direccionamientos de energía sexual entre distintas instancias del aparato psíquico y los objetos del mundo, que cargan como catexis, en 
un proceso de investidura libidinal base de las determinaciones de la vida anímica y, en el sentido amplio que Freud precisó, de las relaciones sexuales.

Durante el estudio de las funciones sexuales pudimos obtener una primera y provisional convicción o, mejor dicho, una vislumbre de dos intelecciones que más tarde se revelarán importantes por todo este ámbito. La primera, que los fenómenos normales y anormales que observamos (es decir, la fenomenologia) demandan ser descritos desde el punto de vista de la dinámica y la economía (en nuestro caso, la distribución cuantitativa de la libido); y la segunda, que la etiología de las perturbaciones por nosotros estudiadas se halla en la historia de desarrollo, o sea, en la primera infancia del individuo. (Freud, 1940 [1938]: 154).

Freud describe en Tres ensayos de teoría sexual las características de la sexualidad en la infancia, describiendo al niño como perverso polimorfo, conjunto de pulsiones parciales y zonas erógenas pujantes por satisfacerse, sin ordenación centralizada ni distribuida de manera afín a un referente u organización. Sin vergüenza, asco o repulsión, los niños y niñas se perciben jugando placenteramente con sus excrementos, o amando pasionalmente a otros -incluidos a quienes encarnan sus progenitores-, mostrando la ausencia de cualquier restricción o reparo en relación al ejercicio de su sexualidad e investimentos libidinales en relaciones de objeto. Sus pulsiones tienden a satisfacerse en el máximo de las posibilidades reales.

\footnotetext{
Es instructivo que bajo la influencia de la seducción el niño pueda convertirse en un perverso polimorfo, siendo descaminado a practicar todas las trasgresiones posibles. Esto demuestra que en su disposición trae consigo la aptitud para ello; tales trasgresiones tropiezan con escasas resistencias porque, según sea la edad del niño, no se han erigido todavia o están en formación los diques anímicos contra los excesos sexuales: la vergüenza, el asco y la moral." (Freud, 1905/1976: 173).
}

Luego el psicoanálisis de Freud definirá en el complejo de Edipo el punto clave en el paso de la sexualidad infantil-perversa hacia a la adulta-normal, desplegando en medio un modelo de escenificación 
familiar que instaura una relación específica del deseo con un ordenamiento, la Ley (agenciada por el padre o sus figuras). Las combinatorias de afectos (amor-odio) hacia las figuras parentales (mamá-papá o sus equivalentes) y su evolución a lo largo de la infancia se vuelven la clave conceptual con la cual pensar la constitución de las instancias y su funcionamiento, así como la economía libidinal en general:

El complejo de Edipo revela cada vez más su significación como fenómeno central del período sexual de la primera infancia. Después cae sepultado, sucumbe a la represión -como decimos-, y es seguido por el periodo de latencia. (...) La niñita, que quiere considerarse la amada predilecta del padre, forzosamente tendrá que vivenciar alguna seria reprimenda de parte de él, y se verá arrojada de los cielos. El varoncito, que considera a la madre como su propiedad, hace la experiencia de que ella le quita amor y cuidados para entregárselos a un recién nacido. (...) La falta de la satisfacción esperada, la continua denegación del hijo deseado, por fuerza determinarán que los pequeños enamorados se extrañen de su inclinación sin esperanzas (Freud, 1924/1976: 181).

Se afirma el carácter determinante de la familia y su estructura (moderna pero universal) como elemento decisivo en la forma de circulación del deseo. Con criterio evolutivo de carácter filogenético, el psicoanálisis de Freud afirma una estructural y estructurante interrupción de aquel cuerpo sin organización del perverso polimorfo, postulando la puesta en marcha del complejo de Edipo y su posterior represión como proceso ordenador universal de la economía libidinal, la vida anímica y de relación con los otros y con el mundo:

La conducta del niño neurótico hacia sus progenitores dentro del complejo de Edipo y de castración sobreabunda en tales reacciones que parecen injustificadas para el individuo y sólo se vuelven concebibles filogenéticamente, por la referencia al vivenciar de generaciones anteriores. (...) La herencia arcaica del ser humano no abarca sólo predisposiciones, sino también contenidos, huellas mnémicas de lo vivenciado por generaciones anteriores. Con ello, tanto el alcance como la significatividad de la herencia arcaica se acrecentarian de manera sustantiva. (Freud, 1940/1976: 96). 
La forma en la que la sexualidad, y por ende la vida, serán pensadas e intervenidas en el psicoanálisis de Freud, depende de la manera en la que las relaciones familiares, declaradas universales en el ser humano, modelen los intercambios de libido y relaciones de objetos hacia una economía sexual normal. La hermenéutica familiarista del psicoanálisis freudiano hizo de la sexualidad un asunto familiar, conectando los procesos deseantes inmanentes con elementos de orden universal y trascendental determinados por la estructura familiar, y una edipización de esas relaciones, remitiéndolas a la gravedad de la figura paterna, en función del mito de Edipo. "Como si Freud hubiese hecho marcha atrás ante este mundo de producción salvaje y de deseo explosivo, y a cualquier precio quisiese poner en él un poco de orden, un orden ya clásico, del viejo teatro griego.” (Deleuze y Guattari, 1972: $60)$.

\section{Familiarismo y reduccionismo frente al deseo descubierto}

El complejo de Edipo funciona en como referente externo, universal y trascendental, tanto en la constitución del psiquismo y la sexualidad como para teorizar sobre ésos fenómenos, haciendo operar un orden mítico que establece de manera inconsciente y filogenética la distribución del deseo, al ponerlo ante, y definirlo en relación a, la Ley instaurada en el encuentro con las figuras paternas. El complejo de Edipo determina la constitución de un aparato psiquico adulto identificado a un normal ordenamiento de las pulsiones y zonas erógenas, dando como resultado un sujeto sexual genitalmente organizado (lo que implica una subordinación a la función reproductiva de este orden filogenético), cuya ordenación tiene por objetos de deseo y modos de satisfacción un conjunto de opciones resultantes en el acontecer y desarrollo del proceso evolutivo, determinado por la condición inicial del complejo.

De esta manera, el deseo se ve encerrado en las dramáticas conflictivas, juego de papeles y escenas de las relaciones intrafamiliares, tan dúctiles 
para luego reducir, interpretación mediante, la totalidad de las experiencias vividas por los pacientes a todo tipo de triangulaciones posibles, determinadas por las múltiples variaciones reducidas en el marco del complejo de Edipo. Deleuze y Guattari describen este postulado del psicoanálisis:

\begin{abstract}
Es un principio por completo ideológico, para la ideología. De hecho, Edipo siempre y tan sólo es un conjunto de llegada para un conjunto de partida constituido por una formación social. Todo se aplica a él, en el sentido que los agentes y relaciones de la producción social, y las catexis libidinales que les corresponden, son volcados en las figuras de la reproducción familiar. En el conjunto de partida hay la formación social, o más bien las formaciones sociales; las razas, las clases, los continentes, los pueblos, los reinos, las soberanías; Juana de Arco y el Gran Mongol, Lutero y la Serpiente azteca. En el conjunto de llegada no hay más que papá, mamá y yo. De Edipo como de la producción deseante es preciso decir: está al final, no al principio (Ibíd.: 107).
\end{abstract}

Los autores postulan el movimiento reaccionario de Freud frente al descubrimiento del deseo: primero se descubre el campo de acción del deseo por sus efectos en el discurso de pacientes, se concibe la energía sexual como elemento determinante de las relaciones interpersonales; luego se reduce en la teoría el alcance y espacio de la producción del deseo, delimitando la circulación y acción en el interior del espacio familiar.

Este es el incurable familiarismo del psicoanálisis, enmarcando el inconsciente en Edipo, ligándolo a él de una parte a otra, aplastando la producción deseante, condicionando al paciente a responder papá-mamá, a consumir siempre el papá-mamá (Ibíd.: 98).

Esta es la doble operación de familiarismo y reduccionismo del deseo, en relación a determinarlo mediante regímenes fijos de tránsito y modulación, tanto en la comprensión de la experiencia como en la producción del saber sobre esos fenómenos. Es dejado por fuera del análisis todo tipo de relaciones con objetos parciales extrafamiliares, 
PALAVRAS. Revista de Epistemología, Metodología y Ética del Psicoanálisis

Número 4 | Diciembre de 2018

extraindividuales, históricos y sociales que conviven con las investiduras libidinales familiares.

El esquizoanálisis no oculta que es un psicoanálisis politico y social, un análisis militante: y ello no porque generalice Edipo en la cultura, en las condiciones ridículas mantenidas hasta ahora. Sino, por el contrario, porque se propone mostrar la existencia de una catexis libidinal inconsciente de la producción social, histórica, distinta de las catexis conscientes que coexisten con ella. (Ibíd.:104).

\section{Economia libidinal y política del deseo}

Deleuze y Guattari propondrán que las pulsiones y catexias no presentan exclusividad en el espacio de la familia, como área natural de constitución y matrizado de una economía libidinal. Ellos afirman la continuidad y contigüidad en el proceso entre lo que nombran como las máquinas deseantes y las máquinas sociales, dado que los objetos parciales investidos en la vida sexual, el trabajo del deseo al investirlos, se realiza sobre la totalidad del cuerpo social y sus elementos conformantes, multiplicidad sin exclusividad de los elementos papámamá-yo y sus figuras extemporáneas. Este trío constituye una retícula fija, producida, que estira la interpretación hacia los límites del triángulo del complejo edipico dejando mucho por fuera.

\footnotetext{
Es todo lo contrario: lo que la libido carga (catexiza) a través de los elementos disjuntos de Edipo, y precisamente en la medida que estos elementos nunca forman una estructura mental autónoma expresiva, son estos cortes extrafamiliares, subfamiliares, estas formas de producción social en relación con la producción deseante (Ibíd.: 104).
}

La separación entre lo que es del orden familiar, alejado del orden histórico y social, conlleva en el psicoanálisis de Freud la premisa de que el segundo orden se constituye por el primero en la instauración del psiquismo, reduciendo la atención y valoración sobre las determinaciones históricas y sociales en la producción de las vidas singulares, al nivel de la producción deseante o economía libidinal. 
Concebir la libido confinada a las determinaciones familiaristas, mediante la postulación del complejo de Edipo, cancela otros posibles tanto en los procesos deseantes como en su teorización, al sujetarlos a las limitaciones que el modo de vida familiar dispone para existir, instaurándolo como condición universal de la vida anímica. Dicen Deleuze y Guattari:

\begin{abstract}
El esquizoanálisis no se propone resolver Edipo, no se propone resolverlo mejor de lo que pueda hacerlo el psicoanálisis edípico. Se propone desedipizar el inconsciente para llegar a los verdaderos problemas. Se propone llegar a estas regiones del inconsciente huérfano, precisamente "más allá de toda ley", donde el problema ni siquiera puede plantearse. Por esto tampoco compartimos el pesimismo que consiste en creer que este cambio, esta liberación, no pueden realizarse más que fuera del psicoanálisis. Por el contrario, creemos en la posibilidad de una reversión interna que convierta a la máquina analítica en una pieza indispensable del aparato revolucionario. (Ibíd.: 88 - 89).
\end{abstract}

El deseo, los fenómenos de la vida anímica y la constitución del psiquismo serán pensados por Deleuze y Guattari como parte específica de una producción más general, producción de producciones, en donde el deseo funciona como principio inmanente de los ciclos en procesos productivos sin fin ni finalidad: "de suerte que todo es producción: producciones de producciones, de acciones y de pasiones; producciones de registros, de distribuciones y de anotaciones; producciones de consumos, de voluptuosidades, de angustias y de dolores" (Ibíd.: 15). Las máquinas deseantes (noción en donde la idea de máquina reemplaza a la de estructura por rebasarla), productoras y producidas, son infundidas por flujos deseantes de toda clase e intensidad, realizando pases y cortes en una red de conexiones que se establece entre máquinas de todo tipo, siendo la conectividad a objetos parciales (otras máquinas) su característica fundamental.

Las máquinas deseantes son siempre binarias, de regla binaria o de régimen asociativo; una máquina siempre va acoplada a otra. La síntesis productiva, la producción de producción, posee una forma conectiva: "Y", "y además"... Siempre hay, además de una máquina productora de un 
flujo, otra conectada a ella y que realiza un corte, una extracción de flujo (el seno-la boca). (Ibíd.: 14).

Desde las coordenadas y fenómenos de orden molecular presubjetivo, carentes de significación pero productores de sentido, hasta los grandes conjuntos molares de ideas que gravan el deseo hacia sí, las máquinas deseantes realizan conexiones en todos los niveles del campo social, entre los que la familia y sus posibilidades son solo una parte, incluso el canal de pasaje, pero no el origen ni el destino de la producción deseante en su totalidad. Deleuze y Guattari afirman lo insidioso de postular el complejo de Edipo, argumentando que al pensar la economía del deseo en esos términos, el complejo de

\footnotetext{
Edipo es un vector: $4,3,2,1,0 \ldots$ Cuatro es el famoso cuarto término simbólico, 3; es la triangulación, 2 con las imágenes duales, 1 es el narcisismo, 0, la pulsión de muerte. Edipo es la entropía de la máquina deseante, su tendencia a la abolición externa. Es la imagen o la representación deslizada en la imagen, el cliché que detiene las conexiones, agota los flujos, introduce la muerte en el deseo y sustituye los cortes por una especie de emplasto - es la Interruptora (los psicoanalistas como saboteadores del deseo) (Ibíd.: 401).
}

\section{Conclusión. La subjetividad maquínica del Esquizoanálisis}

La crítica de Deleuze y Guattari al familiarismo y reduccionismo del psicoanálisis de Freud, nos permite, primero, notar una manera de análisis cuidadosa frente a cualquier sistema de postulados que constituyan una retícula productora y explicativa del devenir humano en su totalidad, utilizando una estructura caracterizada por ser universal y extemporánea.

Esta crítica nos permite agenciar una noción de subjetividad como proceso de producción deseante (modos de ser humano en el mundo) en un campo social dado, al acercar las dimensiones de lo singular y lo social como componentes participantes de un proceso de producción que las envuelve, conjunto de máquinas conectadas en la producción de 
lo que somos, entre los que la familia y sus intersubjetividades específicas son un factor de contingencia antes que una determinación universal. Dicen Deleuze y Guattari:

Al enmarcar la vida del niño en el Edipo, al convertir las relaciones familiares en la universal mediación de la infancia, nos condenamos a desconocer la producción del propio inconsciente y los mecanismos colectivos que se asientan sobre el inconsciente, principalmente todo el juego de la represión originaria, de las máquinas deseantes y del cuerpo sin órganos. Pues el inconsciente es huérfano, y él mismo se produce en la identidad de la naturaleza y el hombre. (Ibíd.: 53).

Desde una posición filosófica materialista del deseo, Deleuze y Guattari sostienen la continuación y conectividad entre los órdenes del proceso de producción deseante en un campo social dado, señalando en Freud y su disposición edípica de la economía libidinal una reducción de la noción y acción del deseo, haciendo universal el proceso por el cual el complejo de "Edipo supone una fantástica represión de las máquinas deseantes." (1972: 12). Así,

el deseo no tiene por objeto a personas o cosas, sino medios enteros que recorre, vibraciones y flujos de todo tipo que desposa, introduciendo cortes, capturas, deseo siempre nómada y emigrante... (...) En resumen, los medios sociales tanto como los biológicos son objeto de catexis del inconsciente que necesariamente son deseantes o libidinales, por oposición a las catexis pre-conscientes de necesidad e interés. (1972: 302).

Estas ideas permiten incluir en el análisis y producción de conocimientos sobre los fenómenos de la vida psíquica y social a la categoría de deseo como elemento transversal a la producción de subjetividad en todos los ámbitos humanos, en todos sus niveles y ordenes (pre-individual, individual, familiar, social, histórico). Esto permite ampliar la atención hacia las múltiples instancias de determinación que producen los fenómenos de vida psíquica y social, extendiendo el territorio conceptual para el análisis de las condiciones que hacen a la producción de subjetividad. 
PALAVRAS. Revista de Epistemología, Metodología y Ética del Psicoanálisis

Número 4 | Diciembre de 2018

\section{Referencias bibliográficas}

Deleuze, G., \& Guattari, F. (1972/1974). El Antiedipo: capitalismo y esquizofrenia. Buenos Aires: Paidós.

Freud, S. (1905/1976). "Tres ensayos de teoría sexual". En Obras Completas, tomo VII (pp. 109-224). Buenos Aires: Amorrortu.

Freud, S. (1923/1976). "Dos artículos de enciclopedia: "Psicoanálisis" y "Teoria de la libido". En Obras Completas, tomo XVIII (pp. 227254). Buenos Aires: Amorrortu.

Freud, S. (1940[1938]/1976). "Esquema del psicoanálisis". En Obras completas, tomo XXIII (pp. 133-170). Buenos Aires: Amorrortu.

Freud, S. (1924/1976). "El sepultamiento del complejo de Edipo". En Obras completas, tomo XIX (pp. 177-187). Buenos Aires: Amorrortu. 